\title{
The accuracy of age estimation from pulp chamber/crown volume ratio of canines obtained by cone beam computed tomography images: an Egyptian study
}

\author{
Fatma M. Elgazzar ${ }^{1 *}$ (D), Mohamed Omar Elboraey ${ }^{2,3}$ and Ghada N. El-Sarnagawy ${ }^{1}$ (D)
}

\begin{abstract}
Background: Globally, the need for an accurate and valid method for age estimation in adults still exists. The aging process is associated with secondary dentine deposition that reduces the volume of teeth pulp. Therefore, dental age could be recognized from the volume of pulp cavity. The aim of this study was to assess the accuracy and validity of pulp chamber/crown volume ratio of maxillary and mandibular canines in estimating age using cone beam computed tomography (CBCT) images in a sample of the Egyptian population.

Results: There were significant strong negative correlations between age and each of the maxillary pulp chamber volume (PCV), mandibular PCV, maxillary pulp chamber/crown volume (PCV/CV) ratio, and mandibular PCV/CV ratio $(p<0.001)$. Furthermore, no significant differences were detected between both sexes regarding the mean maxillary and mandibular PCV and PCV/CV ratios $(p>0.05)$. The best fit regression model for age prediction was as follows: age (years) $=70.21-784.0 x$ maxillary PCV/CV ratio $-1.66 x$ maxillary PCV. The proposed model showed good power of prediction $\left(R^{2}\right.$ adjusted $\left.=0.951\right)$. Additionally, the model was validated on an independent sample of 100 CBCT images with a root mean squared error (RMSE) of 2.86 years.

Conclusion: The obtained valid regression formula in this study can serve as a reliable tool for age estimation in Egyptians. This formula should be further validated on a larger sample size of the Egyptian population that considers more steady age distribution.
\end{abstract}

Keywords: Forensic odontology, Canine pulp chamber volume, Age estimation, Cone beam computed tomography, Egyptians

\section{Background}

Globally, the need for a reliable, simple, and accurate method for age estimation in adults still exists (Marroquin et al. 2017). Precise age estimation is an important clue in criminal and civil events for both living and deceased persons. Legal decisions in many situations such as immigrants, refugees, competency to consent,

\footnotetext{
* Correspondence: fatma.elgazar@med.tanta.edu.eg

'Forensic Medicine and Clinical Toxicology Department, Tanta University Medical Campus, 6th floor Faculty of Medicine, El-Gesh Street, Tanta, El-Gharbia Govenorate 31527, Egypt

Full list of author information is available at the end of the article
}

criminal responsibility, and age falsification depend on the role of forensic practitioners in determining the age of living persons (Ekizoglu et al. 2019). Besides, age identification has a crucial role in reconstructing the biological profile of unidentified dead bodies and body remains in case of mass disasters (Muñoz et al. 2018).

Dental age estimation methods have a great value as the teeth are less affected by genetic, nutritional, and hormonal factors as well as pathological changes compared to the bones (Uğur Aydın and Bayrak 2019). Moreover, they are greatly resistant to various 
environmental conditions like mechanical, chemical, and physical effects (El-Sarnagawy and Yasser 2020).

The teeth consist of enamel, dentin, and pulp. The tooth enamel is the hardest protective outer part and contains minerals of $96 \%$. The inner dental pulp is composed of mesenchymal tissue. Also, it consists of a large central pulp chamber which imitates the whole shape of the tooth crown (Melo and Ata-Ali 2017). The middle dentin layer is formed throughout the individual's life by odontoblasts at the dentin-pulp border (Tjäderhane and Paju 2019). There are 3 known types of dentine; the primary dentine that is formed until the tooth becomes functional, the secondary dentine that is formed after root completion, and the tertiary dentine which is formed only as a reaction to injury (Venkatesh et al. 2014). It has been reported that the pulp-dentin complex (PDC) shows age-related changes due to the secondary dentine accumulation (Kavas and Tümen 2019). Therefore, the pulp chamber volume could be altered by the aging process (Gulsahi et al. 2018).

Dental age estimation in adults has been advanced with the introduction of non-invasive imaging technologies in forensic case work. Many radiological techniques have been established to estimate age by measuring the pulp cavity dimensions (Carew and Errickson 2019). Many studies revealed a strong correlation between the pulp cavity measurements and chorological age by using bi-dimensional periapical and panoramic radiographs (Zaher et al. 2011; Limdiwala and Shah 2013). However, the accuracy of these conventional methods has been limited by some drawbacks such as image distortion and superimposition, different magnifications, and the availability of linear measurements only (Schmeling et al. 2016).

The development of a three-dimensional image cone beam computed tomography (CBCT) has provided many advantages including high-quality images with greater discriminatory power between structures as well as accurate measurement of tooth and pulp dimensions in multiple planes without superimposition or distortion. Regarding the risk of radiation, CBCT radiation dose is much higher than conventional radiology, but its risk can be minimized by following certain task specific protocols (Scarfe and Farman 2008; Li 2013). Also, in comparison with Micro-CT, CBCT offers large scanning area and can be performed without teeth extraction (Gulsahi et al. 2018).

Forensic application of CBCT images for dental age estimation has been previously studied. However, these studies investigated the relation of either pulp chamber linear dimensions or pulp/tooth area ratio with age (Nemsi et al. 2017; Uğur Aydın and Bayrak 2019; Salemi et al. 2020). There were inconsistent results with a variable strength of linear and non-linear correlations
(Kazmi et al. 2019). Additionally, only one study investigated the 3D pulp/tooth volume ratio of mandibular canines for age estimation in a sample of Egyptians, revealing an accuracy of $75.5 \%$. Hence, there is a need to explore the differential accuracy of maxillary and mandibular canines and whether the specific measurement of the pulp chamber could add to the accuracy of age prediction rather than the whole tooth volume.

To the best of our knowledge, the relation between pulp chamber/crown volume ratio and age in Egyptians was not previously investigated. Therefore, the aim of this study was to assess the accuracy and validity of pulp chamber/crown volume $(\mathrm{PCV} / \mathrm{CV})$ ratio of maxillary and mandibular canines in estimating age by CBCT images in a sample of the Egyptian population.

\section{Methods}

\section{Study design, settings, and ethical considerations}

In the present retrospective study, CBCT scans of patients were selected from the archives of the Department of Oral Medicine, Periodontology, Oral Diagnosis, and Radiology, Faculty of Dentistry, Tanta University, during the period from January 2019 to January 2020. The CBCT scans had been requested for other diagnostic or therapeutic conditions not related to this study.

The study was approved by the Research Ethics Committee (REC), Faculty of Medicine, Tanta University (Approval number: 33677/2/20). Data was anonymized (coded identity) where only the age, sex, and details of CBCT scanning were provided.

\section{Eligibility criteria}

The study included 200 CBCT images of maxillary and mandibular canines (98 males and 102 females) with chronological age ranging from 15 to 60 years. The chorological age was identified from patients' data in the department archives. Only clearly visible CBCT images with high resolution that showed fully erupted permanent maxillary and mandibular canines with completely normal root and obvious cementoenamel junction (CEJ) were included. Maxillary and mandibular canines (either right or left) were selected as they have the largest root and the highest persisting rate in the dental arch until old age (Afify et al. 2019).

The canines showed caries, significant wear or attrition, restoration, impaction, root resorption, traumatic lesions, cysts or tumors, and dental anomalies, pathology or calcification were excluded to avoid any changes in pulp volumes due to pathological dentin deposition. Additionally, prosthetic crowns or endodontic treatment were excluded to avoid any iatrogenic changes of the normal pulp chamber and/or tooth crown dimensions. 


\section{Sample size}

Sample size was calculated with $G *$ Power software program version 3.1. An effect size of 0.2 representing the assumed difference between the mean observed and predicted ages was chosen, with an alpha level of 0.05 and a target power of $80 \%$. The required sample size was found to be 200 CBCT scans.

\section{$\mathrm{CBCT}$ image gaining}

All CBCT images were obtained by CRANEX 3D machine (Soredex, Helsinki, Finland). Exposure parameters were tube voltage of $80 \mathrm{kVp}$, milliampere of $4 \mathrm{mAs}$, and scanning time of $12.01 \mathrm{~s}$. The included field of view (FOV) was $50 \mathrm{~mm}$ height $\times 55 \mathrm{~mm}$ diameter according to the most recommended parameters for accurate volume measurement (Yilmaz et al. 2019). Then, the retrieved images were reconstructed with a voxel size of $0.15 \mathrm{~mm}^{3}$.

All the collected CBCT images were exported in Digital Imaging and Communication on Medicine (DICOM) format. The DICOM files were imported to ITK-SNAP software, version 3.8.0 (U.S. National Institute of Biomedical Imaging and Bio Engineering), for further 3D analysis and calculations. The contrast and brightness of images were adjusted by the image processing tool in the software program for optimum visualization to ensure accurate building of $3 \mathrm{D}$ models of the canines' pulp chamber and crown.

\section{Measurements}

The cemento-enamel junction (CEJ) was used as a reference point for measuring both the pulp chamber and crown volumes since it is the line separating the crown and the root in addition to being fixed (Vandana and Haneet 2014).

First, the volume of pulp chamber was measured mainly in the axial view through masking and segmentation. Then, the dimensions were rechecked through the cross-sectional, sagittal, and coronal views to ensure high accuracy of the included dimensions. After checking the correct dimensions of the pulp chamber from different views, its volume was automatically calculated $\left(\mathrm{mm}^{3}\right)$ by ITK-snap software, with the reconstruction of $3 \mathrm{D}$ image of the canines' pulp chamber and crown (Fig. 1). The pulp chamber volume was measured from the tip of pulp chamber horn to the level of the pulp at CEJ, while the crown volume was measured from the cusp tip to the CEJ (Fig. 2). The measured crown volume was not included in the pulp chamber to avoid duplication of the pulp chamber volume.

It has been reported that the crown volume is vulnerable to many factors rather than age such as periodontal condition, cusp height, bite strength, saliva quality and quantity, and other chemical and mechanical factors (Bajpai et al. 2013). Hence, the pulp chamber volume $(\mathrm{PCV})$ and pulp chamber/crown volume $(\mathrm{PCV} / \mathrm{CV})$
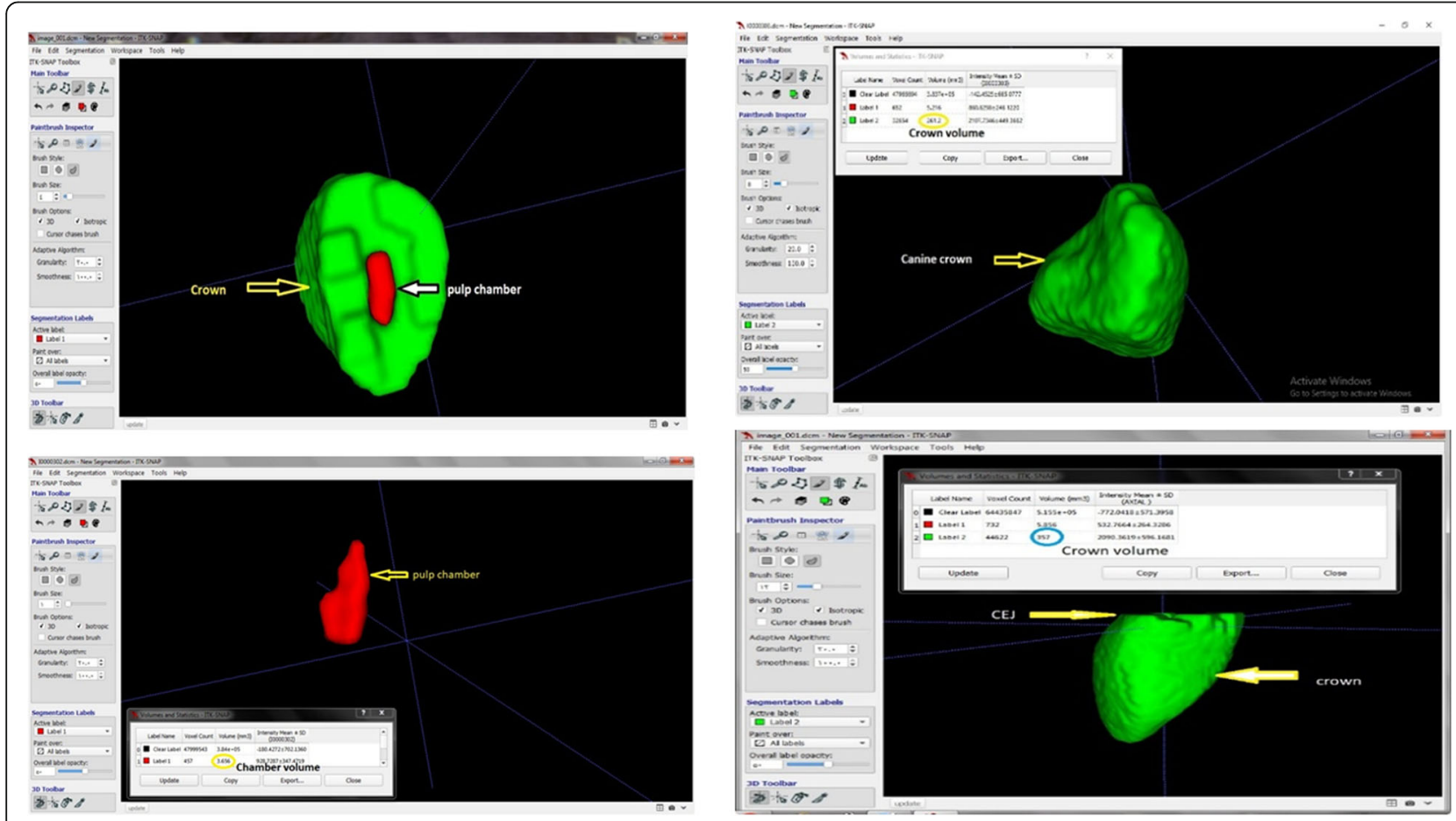

Fig. 1 Reconstructed 3D images showing canine pulp chamber (red) and crown (green) at the level of cemento-enamel junction (CEJ) through an axial view 


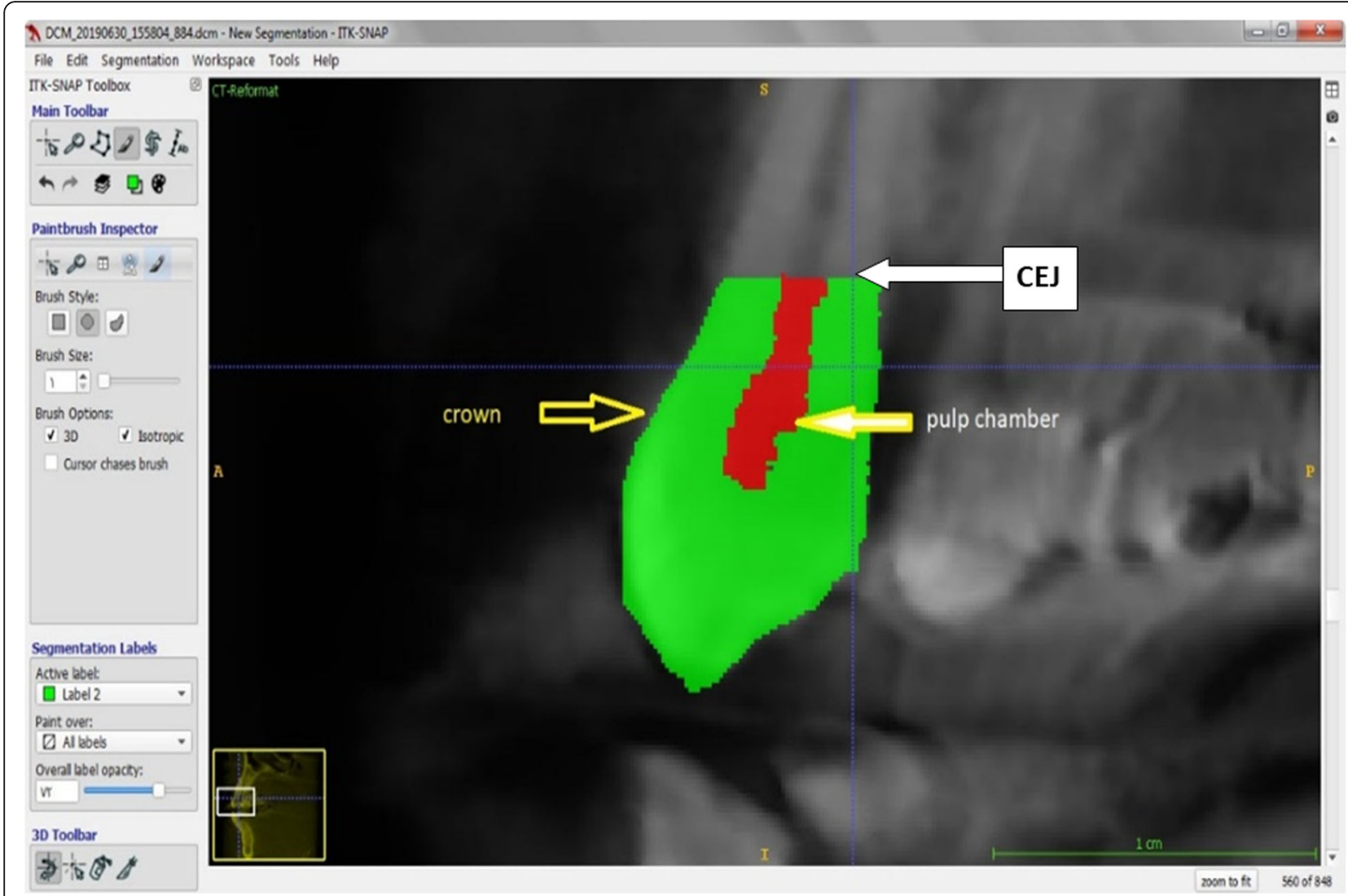

Fig. 2 Canine pulp chamber (red) and crown (green) with sharp demarcation and both ended at the cemento-enamel junction (CEJ) through a cross-sectional view

ratios were used as independent parameters for age estimation in this study.

\section{Measurement reliability}

To maintain the reliability of measurements, 30 images out of the 200 included CBCT images in the study were randomly remeasured 2 weeks after the initial evaluation by the same observer. Concurrently, 30 images were checked by another examiner to assess the interobserver reliability.

\section{Model validation}

The best fit regression model was calculated from the measurements showing significant correlation with chronological age. Subsequently, the regression equation was validated to determine the model's accuracy in age prediction. This was done on another sample of 100 CBCT images of maxillary and mandibular canines (50 males and 50 females) with the same mentioned eligibility study criteria.

\section{Statistical analysis}

Statistical analysis and presentation of data was conducted using SPSS (Statistical Package for the Social Sciences) version 22 computer program. The categorical data were presented as numbers and percentages. The continuous numerical data were tested for normality by Shapiro-Wilk test; they were found to be normally distributed data and expressed as mean \pm standard deviation. Independent $T$ test was used for comparing the studied variables between both sexes, while paired $T$ test was used for comparing the actual and predicted ages of subjects in the validation sample. Pearson's correlation coefficient was applied to investigate the association of each of the studied variables with age as well as the correlation between the actual age and the estimated one. Furthermore, forward multiple linear regression analysis including the studied four variables was applied to detect the best fit regression model for age prediction. Validation of the regression model was done on an independent new set of cases. The accuracy of prediction was evaluated by the calculation of the root mean squared error (RMSE) as follows: $\sqrt{\frac{\Sigma\left(\boldsymbol{Y}-\boldsymbol{Y}^{\prime}\right)^{2}}{N}}$. Paired and unpaired $T$ tests were 
used to compare intra- and inter-observer data. Additionally, Pearson's correlation coefficient was calculated to assess the intra- and interrater reliabilities. The level of statistical significance was considered at $p<0.05$.

\section{Results}

Repeated measurements for 30 images out of the studied 200 CBCT images revealed no statistically significant intra- or inter-observer differences $(p>0.05)$. Additionally, the intra- and inter-rater reliabilities were excellent (correlation coefficient $=0.95$ ) .

Table 1 illustrates age and sex distribution of the studied subjects. Females and males showed homogenous distribution and represented $51.0 \%$ and $49.0 \%$, respectively. The mean age of participants was $36.83 \pm 12.1$ years. There were no statistically significant differences between males and females regarding the mean maxillary PCV, mandibular PCV, maxillary $\mathrm{PCV} / \mathrm{CV}$ ratio, or mandibular $\mathrm{PCV} / \mathrm{CV}$ ratio $(p>0.05)$ as shown in Table 2.

Figures 3 and 4 demonstrate significant strong negative correlations between age and each of the maxillary $\mathrm{PCV}$, mandibular $\mathrm{PCV}$, maxillary $\mathrm{PCV} / \mathrm{CV}$ ratio, and mandibular $\mathrm{PCV} / \mathrm{CV}$ ratio $(p<0.001)$. Maxillary $\mathrm{PCV} /$ $\mathrm{CV}$ ratio showed the strongest inverse correlation with age $(r=-0.96)$, while mandibular PCV showed the least correlation coefficient $(r=-0.90)$.

In order to detect the best fit regression model for data, multiple linear regression analysis including the studied four variables by using forward method was applied. It revealed that both maxillary PCV and $\mathrm{PCV} / \mathrm{CV}$ ratios contributed significantly in age prediction $(p<0.001)$ with the following regression equation: age (years) $=70.21-784.0 x$ maxillary $\mathrm{PCV} / \mathrm{CV}$ ratio $-1.66 x$ maxillary $\mathrm{PCV}$. This model

Table 1 Age and sex distribution of the studied subjects ( $N=$ 200)

\begin{tabular}{|c|c|c|c|c|c|c|}
\hline \multirow{3}{*}{$\begin{array}{l}\text { Age } \\
\text { groups } \\
\text { (years) }\end{array}$} & \multicolumn{6}{|l|}{ Sex } \\
\hline & \multicolumn{2}{|c|}{ Female } & \multicolumn{2}{|c|}{ Male } & \multicolumn{2}{|c|}{ Total } \\
\hline & $N$ & $\%$ & $N$ & $\%$ & $N$ & $\%$ \\
\hline $1(<20)$ & 11 & 52.4 & 10 & 47.6 & 21 & 100.0 \\
\hline $2(20-24)$ & 12 & 50.0 & 12 & 50.0 & 24 & 100.0 \\
\hline $3(25-29)$ & 14 & 56.0 & 11 & 44.0 & 25 & 100.0 \\
\hline $4(30-34)$ & 9 & 47.4 & 10 & 52.6 & 19 & 100.0 \\
\hline $5(35-39)$ & 11 & 52.4 & 10 & 47.6 & 21 & 100.0 \\
\hline $6(40-44)$ & 13 & 48.1 & 14 & 51.9 & 27 & 100.0 \\
\hline $7(45-49)$ & 10 & 47.6 & 11 & 52.4 & 21 & 100.0 \\
\hline $8(50-54)$ & 12 & 54.5 & 10 & 45.5 & 22 & 100.0 \\
\hline $9(55-60)$ & 10 & 50.0 & 10 & 50.0 & 20 & 100.0 \\
\hline Total & 102 & 51.0 & 98 & 49.0 & 200 & 100.0 \\
\hline
\end{tabular}

showed good power of prediction (coefficient of determination: $R^{2}$ adjusted $=0.951$ ) as shown in Table 3 .

\section{Validation}

The best fit regression model (age (years) $=70.21-$ $784.0 x$ maxillary PCV/CV ratio - $1.66 x$ maxillary PCV) was validated on an independent sample of $100 \mathrm{CBCT}$ images that was held back for this purpose. The calculated root of the mean squared error (RMSE) between the actual and estimated ages was 2.86 years. Furthermore, the actual and estimated ages were compared by paired $T$ test in each age group as shown in Table 4 . Non-significant differences were detected in the age groups from 30 to 44 years old $(p>0.05)$, whereas other age groups showed significant differences $(p<0.05)$. It was observed that the age groups younger than 40 years old exhibited higher predicted ages than the actual ones. Alternatively, there was underestimation of the predicted age in the older age groups.

\section{Discussion}

The present study demonstrated significant strong inverse correlations between the chronological age and each of maxillary PCV, mandibular PCV, maxillary PCV/ $\mathrm{CV}$ ratio, and mandibular $\mathrm{PCV} / \mathrm{CV}$ ratio. Maxillary $\mathrm{PCV} / \mathrm{CV}$ ratio showed the strongest correlation with age $(r=-0.96)$, while mandibular PCV showed the least correlation coefficient $(r=-0.90)$. Moreover, this work revealed a valid regression equation for age estimation in Egyptian adults (age (years) $=70.21-784.0 x$ maxillary PCV/CV ratio $-1.66 x$ maxillary PCV) with high accuracy of \pm 2.86 years.

Our work was based on the well-known physiological process of age-related secondary dentine deposition which results in the reduction of the teeth pulp cavity. This phenomenon is characterized by being persistent as long as the tooth is vital. Furthermore, secondary dentine deposition along the internal surface of teeth is well secured against various environmental conditions (Carvalho and Lussi 2017). Therefore, different odontometric investigations of the teeth pulp have been established as predictors of chorological age (Marroquin et al. 2017).

It has been reported that the secondary dentin deposition is not homogenous in all pulp surfaces. It is mainly formed on the roof and floor of the pulp chamber, resulting in an asymmetrical decrease in its shape and size. Consequently, the main dentine-related alterations take place in the pulp chamber (Arora et al. 2016). Additionally, the pulp chamber shows the best pulp dentin distinction in CBCT (Krasner and Rankow 2004). Hence, the pulp chamber volume was selected in this study rather than the whole tooth pulp volume in order to obtain accurate measurements. 
Table 2 Comparison of maxillary and mandibular pulp chamber volumes and pulp chamber/crown volume ratios between both sexes

\begin{tabular}{|c|c|c|c|c|c|}
\hline & & \multicolumn{2}{|l|}{ Sex } & \multicolumn{2}{|c|}{ Independent $T$ test } \\
\hline & & $\begin{array}{l}\text { Female } \\
N=102\end{array}$ & $\begin{array}{l}\text { Male } \\
N=98\end{array}$ & $\bar{t}$ & $P$ \\
\hline \multirow[t]{2}{*}{ Maxillary PCV $\left(\mathrm{mm}^{3}\right)$} & Mean & 8.21 & 7.92 & 0.765 & 0.445 \\
\hline & SD & 2.61 & 2.82 & & \\
\hline \multirow[t]{2}{*}{ Mandibular PCV $\left(\mathrm{mm}^{3}\right)$} & Mean & 8.12 & 7.82 & 0.784 & 0.434 \\
\hline & SD & 2.52 & 2.76 & & \\
\hline \multirow[t]{2}{*}{ Maxillary PCV/CV ratio } & Mean & 0.026 & 0.025 & 0.575 & .566 \\
\hline & SD & .01 & .01 & & \\
\hline \multirow[t]{2}{*}{ Mandibular PCV/CV ratio } & Mean & 0.025 & 0.024 & 0.570 & .521 \\
\hline & SD & .01 & .01 & & \\
\hline
\end{tabular}

Permanent maxillary and mandibular canines were selected in this study as they frequently remain intact until old age. This is attributed to the characteristic shape of the canine's crown part that keeps it clean along with its effective self-cleansing consistency. Hence, canines are less liable to decay or caries. Moreover, canines are well anchored in the jaws and have a reasonably simple anatomy of a large single root and great well-defined pulp dimensions (Farhadian et al. 2019). In comparison, incisors are frequently exposed to mechanical or physical traumas and predisposed to periodontal diseases. Therefore, they often miss their dental crown. Similarly, molar teeth are greatly liable for caries and restoration (Americano et al. 2017). Accordingly, similar studies have recommended canines for measuring the pulp size rather than other teeth groups (Gulsahi et al. 2018; Afify et al. 2019; Kazmi et al. 2019).

In addition to measuring the maxillary and mandibular canines PCV, the ratio between pulp chamber volume and crown volume was calculated to be investigated in this study as it minimizes the individual variations regarding tooth size and decreases the possible dimensional variations during $\mathrm{CBCT}$ recording, separation, segmentation, and calculation processes (Gulsahi et al. 2018).

The current study revealed no significant differences in the intra- or inter-observer repeated measurements, with excellent intra- and inter-rater reliabilities. This finding indicates high reproducibility and favors the applicability of the present study.

The main objective of this study was to develop a reliable method for dental age estimation in adults. Therefore, a sufficiently large sample constituting wide variability of the investigated parameters was used. Additionally, the recruited subjects were evenly distributed for age and sex with nearly equal-size 5year-interval age groups; this guaranteed the development of accurate model of age prediction for various
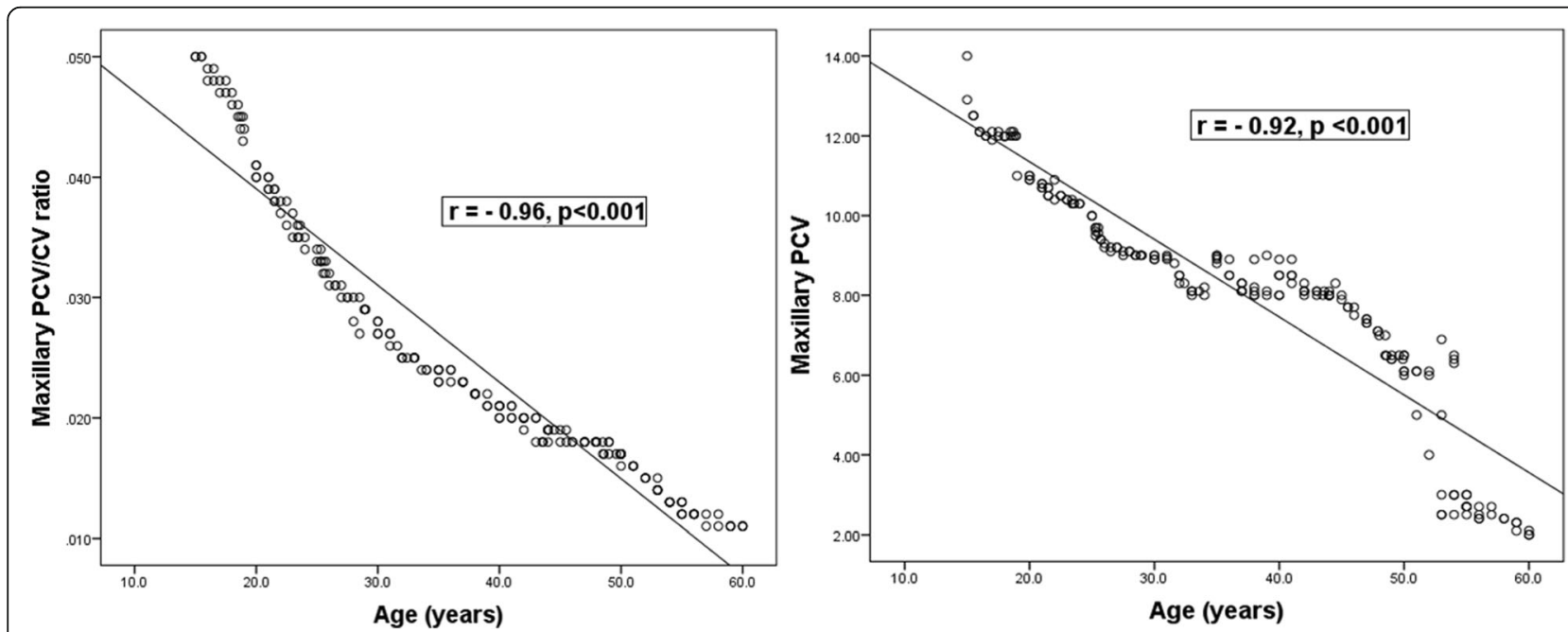

Fig. 3 Correlation of maxillary PCV and PCV/CV ratio with the chronological age of the studied subjects $(N=200)$ 

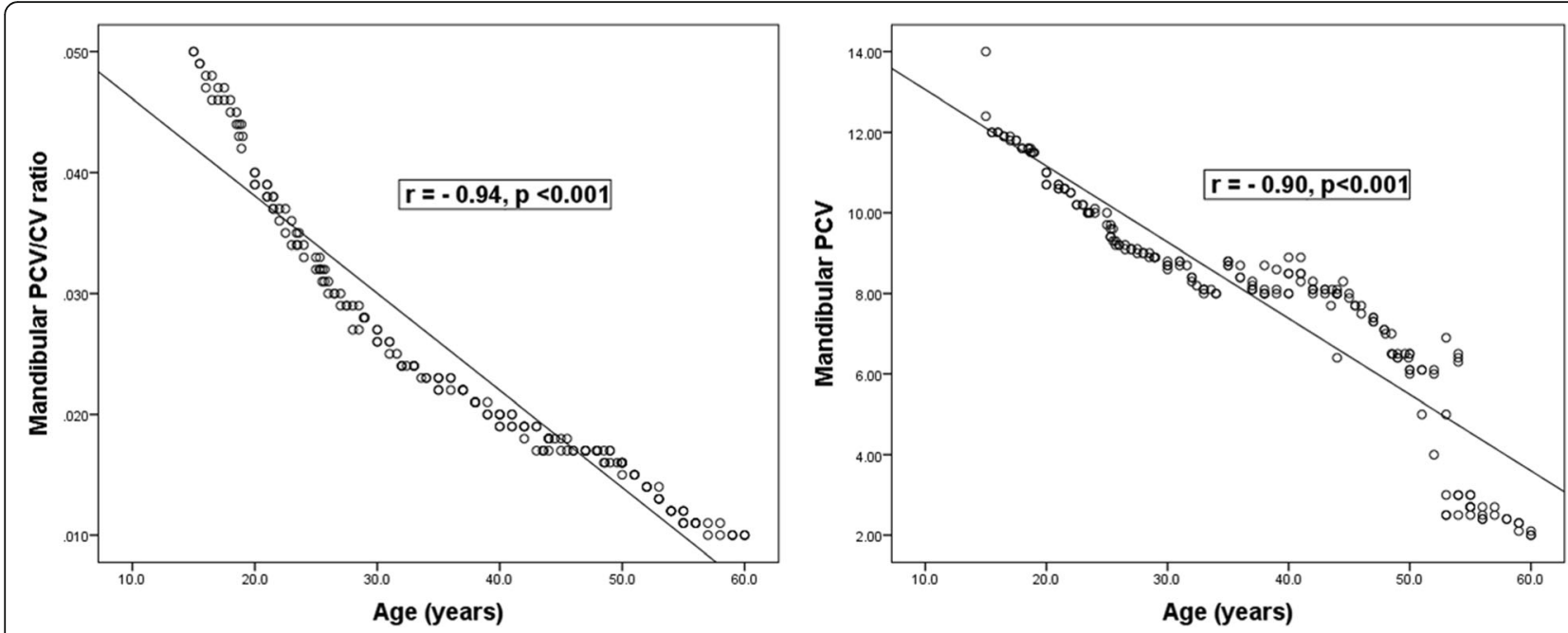

Fig. 4 Correlation of mandibular PCV and PCV/CV ratio with the chronological age of the studied subjects $(N=200)$

legal and civil conditions in both living and dead individuals.

Regarding sexual dimorphism, the present study did not demonstrate any significant differences between males and females regarding each of maxillary PCV, maxillary $\mathrm{PCV} / \mathrm{CV}$ ratio, mandibular $\mathrm{PCV}$, or mandibular PCV/CV ratio. Similarly, various studies revealed no significant differences between both sexes in the canine teeth of Egyptians (Afify et al. 2014; Afify et al. 2019; Salemi et al. 2020), Tunisians (Nemsi et al. 2017), Indians (Saxena 2011), and Portuguese (Cameriere et al. 2009). Conversely, a study performed on 717 CBCT images of Pakistani origin subjects revealed significant differences of the canine's pulp volumes between males and females (Kazmi et al. 2019). It seems that sex differences of the teeth are related to the selected teeth and measurements as well as the applied techniques, methods, and the studied population (Marroquin et al. 2017). Furthermore, De Angelis et al. (2015) reported that sex had no significant influence on regression models for age estimation using PCV related to the entire teeth volume in male and female groups, with possible adoption of a common regression model. Hence, sex was not involved in the regression equations of this study.

The present study showed significant inverse correlation between chronological age and each of the maxillary canine PCV and PCV/CV ratio as well as mandibular canine $\mathrm{PCV}$ and $\mathrm{PCV} / \mathrm{CV}$ ratio. This is in agreement with Elmoazen et al. (2017) and Adisen et al. (2020) who demonstrated significant negative correlation between age and pulp/tooth volume ratio of canines $(r=-0.869$ and $r=-$ 0.76 , respectively). Additionally, a significant negative correlation between the ratio of canine's pulp/tooth area and age in Egyptians was reported in previous studies (Afify et al. 2019; Salemi et al. 2020). Conversely, Kazmi et al. (2019) reported that each of the maxillary and mandible canine pulp volumes had non-linear correlation with chronological age in the Pakistani population. They observed consistent decrease of the pulp volume as the individual's age increases; however, the rate of change in the pulp volume was not fixed among different early, middle, and old ages. They attributed their findings to the heterogenous large studied sample.

Compared to our findings, previous studies which investigated other teeth types also demonstrated variable strengths of significant negative correlations of pulp measurements with age including maxillary and mandibular molars (Kavas and Tümen 2019), premolars pulp to tooth ratio (Cameriere et al. 2012), and the pulp volume of maxillary central incisors (Asif et al. 2018).

Table 3 Multiple linear regression analysis (forward method) for age prediction by the studied variables

\begin{tabular}{|c|c|c|c|c|c|c|c|}
\hline \multirow[t]{2}{*}{ Model } & \multicolumn{2}{|c|}{ Unstandardized Coefficients } & \multirow{2}{*}{$\begin{array}{l}\text { Standardized Coefficients } \\
\text { Beta }\end{array}$} & \multirow[t]{2}{*}{$t$} & \multirow[t]{2}{*}{$P$ value } & \multicolumn{2}{|c|}{$95.0 \%$ Confidence Interval for B } \\
\hline & B & Std. Error & & & & Lower Bound & Upper Bound \\
\hline (Constant) & 70.21 & .652 & & 107.763 & $<0.001^{*}$ & 68.923 & 71.493 \\
\hline Maxillary PCV/CV ratio & -784.0 & 41.264 & -.654 & -19.000 & $<0.001^{*}$ & -865.385 & -702.634 \\
\hline Maxillary PCV (mm³) & -1.66 & .165 & -.347 & -10.069 & $<0.001^{*}$ & -1.982 & -1.333 \\
\hline
\end{tabular}

*Significant at $p<0.05$ 
Table 4 Comparison between the actual and predicted age in the validation sample $(N=100)$

\begin{tabular}{|c|c|c|c|c|c|}
\hline \multirow{2}{*}{\multicolumn{2}{|c|}{$\begin{array}{l}\text { Age groups } \\
\text { (years) }\end{array}$}} & \multirow{2}{*}{$\begin{array}{l}\text { Actual } \\
\text { age } \\
\text { (years) }\end{array}$} & \multirow{2}{*}{$\begin{array}{l}\text { Predicted } \\
\text { age } \\
\text { (years) }\end{array}$} & \multicolumn{2}{|l|}{ Paired $T$ test } \\
\hline & & & & $\begin{array}{l}\text { Difference } \\
\text { (predicted - actual) }\end{array}$ & $P$ value \\
\hline \multirow[t]{2}{*}{$1(<20)$} & Mean & 17.20 & 19.85 & 2.60 & $<0.001^{*}$ \\
\hline & SD & 1.4 & 1.6 & 1.3 & \\
\hline \multirow[t]{2}{*}{$2(20-24)$} & Mean & 22.00 & 25.00 & 3.03 & $<0.001^{*}$ \\
\hline & SD & 1.3 & 1.5 & 0.77 & \\
\hline \multirow[t]{2}{*}{$3(25-29)$} & Mean & 26.70 & 29.20 & 2.50 & $<0.001^{*}$ \\
\hline & SD & 1.4 & 1.8 & 0.64 & \\
\hline \multirow[t]{2}{*}{$4(30-34)$} & Mean & 31.90 & 32.05 & 0.13 & 0.062 \\
\hline & SD & 1.4 & 1.5 & 0.28 & \\
\hline \multirow[t]{2}{*}{$5(35-39)$} & Mean & 36.90 & 37.14 & 0.24 & 0.056 \\
\hline & SD & 1.4 & 1.4 & 0.54 & \\
\hline \multirow[t]{2}{*}{$6(40-44)$} & Mean & 42.30 & 41.90 & -0.42 & 0.063 \\
\hline & SD & 1.6 & 2.2 & 1.1 & \\
\hline \multirow[t]{2}{*}{$7(45-49)$} & Mean & 47.50 & 45.89 & -1.59 & $<0.001^{*}$ \\
\hline & SD & 1.5 & 1.4 & 0.47 & \\
\hline \multirow[t]{2}{*}{$8(50-54)$} & Mean & 52.20 & 48.72 & -3.45 & $<0.001^{*}$ \\
\hline & SD & 1.6 & 1.7 & 1.1 & \\
\hline \multirow[t]{2}{*}{$9(55-60)$} & Mean & 57.10 & 52.30 & -4.75 & $<0.001^{*}$ \\
\hline & SD & 1.9 & 1.9 & 0.55 & \\
\hline
\end{tabular}

*Significant at $p<0.05$

Interestingly, the maxillary $\mathrm{PCV} / \mathrm{CV}$ ratio in our study showed stronger negative correlation with age $(r=-0$. 96) than mandibular PCV $(r=-0.90)$. This finding is comparable with a previous Egyptian study by Afify et al. (2019) who found that the pulp/tooth area ratio of maxillary canine showed a stronger positive correlation with age $(r=-0.919)$ than mandibular canine $(r=-0.827)$. Moreover, Singal et al. (2019) found that the coronal pulp cavity index of maxillary canine was better correlated with chronological age compared to the mandibular canine. Gulsahi et al. (2018) reported more uniform and consistent manner of secondary dentine deposition with age in maxillary canines compared to mandibular canines. This might explain the observed better results with the use of maxillary canines.

This work revealed the best fit regression equation for age estimation in Egyptian adults (age (years) $=70.21-$ $784 x$ maxillary PCV/CV ratio $-1.66 x$ maxillary PCV) that exhibited good power of age prediction (coefficient of determination $R^{2}$ adjusted $=0.951$ ). This model has been validated in an independent sample of 100 subjects and revealed high accuracy with RMSE of 2.86 years. Accordingly, the availability of only single maxillary canine tooth could efficiently help in the age estimation of adults.

Dental age estimation has been investigated in many studies which lack standardization of the studied techniques and the parameters used to assess the accuracy and reliability of each method. In addition, there were wide variations in the size of these studies' samples. All of these limitations constitute difficulties in comparing the results of these studies. For consistency, our results were compared with the studies based on the secondary dentine deposition as well as linked volumetric or area changes in canines. Furthermore, the only shared comparable parameter between these studies was the coefficient of determination $R^{2}$ as stated by Tardivo et al. (2014). The coefficient of determination represents the percentage of variation in age that can be explained by the pulp volume measurements, and hence the power of prediction.

Some previous studies which evaluated age estimation from the canine's pulp volume in some countries and populations displayed regression models with lower coefficients of determination including studies in France $\left(R^{2}\right.$ varied between 0.32 and 0.47) (Tardivo et al. 2011), Indonesia $\left(R^{2}=75.3 \%\right)$ (Hidayat et al. 2018), and India $\left(R^{2}=75.5 \%\right)$ (Jagannathan et al. (2011), as well as studies in subjects of Pakistani origin $\left(R^{2}=0.33\right)$ (Kazmi et al. 2019) and Egyptians (pulp volume of mandibular canines) $\left(R^{2}=75.5 \%\right)$ (Elmoazen et al. 2017).

In agreement with our regression model, a study of pulp/tooth volume ratio of different types of teeth in 210 CT scans of French subjects revealed the best performance for maxillary canines, with comparable high power of prediction $\left(R^{2}\right.$ adjusted $\left.=0.964\right)$ and high validity $($ RMSE $=0.958)$ (Tardivo et al. 2014). Moreover, Cameriere et al. (2009) identified similar high predictive power of the pulp tooth area ratio of both maxillary and mandibular canines in the Portuguese population that explained $97 \%$ of the total variance in age, with mean prediction errors of 2.37 and 2.55 years, respectively. Further comparable models were recorded in the Karnataka population $\left(R^{2}=0.960\right)$ with standard error of estimate (SEE) of 3.0186 years (Juneja et al. 2014) and the Egyptian population $\left(R^{2}=91 \%\right.$, SEE $= \pm 4.76$ ) (Afify et al. 2019).

The observed variation in the predictive power of various regression models is related to the sample size, distribution of age grouping, technical procedures, and environmental and ethnic factors (Salemi et al. 2020).

In this study, the validation of regression model revealed non-significant differences between predicted and observed ages in the age groups from 30 to 44 years old $(p>0.05)$. However, the predicted age was overestimated in younger age groups and underestimated in older age groups, with RMSE between the actual and estimated ages not exceeding 2.63 years. This is consistent with Salemi et al. (2020) who demonstrated that the 30-40 age group was the only valid group for regression model 
of age estimation from pulp tooth area ratio in the maxillary canines of Egyptians, with significant differences between the actual and estimated ages of no more than 5 years among other age groups. Similarly, another study in the Malaysian population also revealed higher errors of age prediction from the pulp volume of maxillary canines in the age group of 46-65 years old (Asif et al. 2019). In the Brazilian population, Andrade et al. (2019) demonstrated high accuracy of age estimation from the upper incisors and canines in individuals older than 35 years. This finding could be attributed to the consistent dentine deposition which occurs at regular intervals in the middle age; however, this deposition is rapid both in younger ages until 30 years old and again in the older age groups (Kazmi et al. 2019). Conversely, other studies demonstrated no significant differences between the estimated and chronological ages among different age groups (Mathew et al. 2013; Juneja et al. 2014).

\section{Conclusions}

Our results indicated strong inverse linear correlations between each of PCV and PCV/CV ratio of both maxillary and mandibular canines and the chronological age. A valid regression formula was obtained in this study which could serve as a reliable tool for age estimation in Egyptians, with a mean error of no more than 3 years. Moreover, the valid regression model was more suitable for age estimation in the age groups from 30 to 44 years. This model is specific to the population and characteristics of the sample from which it is retrieved. For model extrapolation, it is necessary to be further validated on a larger sample size of Egyptians that consider more steady age distribution.

\section{Abbreviations \\ PCV: Pulp chamber volume; PCV/CV: Pulp chamber/crown volume; RMSE: Root mean squared error}

\section{Acknowledgements}

Not applicable

\section{Authors' contributions}

FE and GE contributed to the idea of the research, the study design, and the writing of the research. Additionally, FE performed the statistical analysis, interpreted the data, and revised and published the article. ME shared in the collection of the data and rating of the cone beam images. The authors read and approved the final manuscript.

\section{Funding}

This research was not financially supported by any organization.

\section{Availability of data and materials}

Data supporting our findings can be found with the corresponding author on reasonable request. Data will not be shared, as it contains personal information. Please contact the author for data requests.

\section{Ethics approval and consent to participate}

The study was approved by the Research Ethics Committee (REC), College of Medicine, Tanta University (Approval number: 33677/2/20). Confidentiality of data was maintained by making code number for each participant (coded identity). Consent to participate from participants is not applicable as the data was obtained from the electronic database.

Consent for publication

Not applicable

\section{Competing interests}

The authors declare that they have no competing interests.

\section{Author details}

${ }^{1}$ Forensic Medicine and Clinical Toxicology Department, Tanta University Medical Campus, 6th floor Faculty of Medicine, El-Gesh Street, Tanta, El-Gharbia Govenorate 31527, Egypt. ${ }^{2}$ Oral Medicine, Periodontology, Oral Diagnosis and Radiology Department, Faculty of Dentistry, Tanta University, Tanta, Egypt. ${ }^{3}$ Periodontology Department, College of Dentistry, Taibahu University, Medina, Kingdom of Saudi Arabia.

Received: 22 May 2020 Accepted: 26 November 2020

Published online: 05 December 2020

\section{References}

Adisen MZ, Keles A, Yorubulut S, Nalcaci R (2020) Age estimation by measuring maxillary canine pulp/tooth volume ratio on cone beam $\mathrm{CT}$ images with two different voxel sizes. Aust J Forensic Sci 52(1):71-82. https://doi.org/10.1080/ 00450618.2018 .1474947

Afify M, Salem W, Mahmoud NJJFR (2019) Age estimation from pulp/tooth area ratio of canines using cone-beam computed tomography image analysis: study of an Egyptian sample. J Forensic Res 10(434):2

Afify MM, Zayet MK, Mahmoud NF, Ragab ARJJFR (2014) Age estimation from pulp/tooth area ratio in three mandibular teeth by panoramic radiographs: study of an Egyptian sample. J Forensic Res 5(3):1

Americano GCA, Jacobsen PE, Soviero VM, Haubek D (2017) A systematic review on the association between molar incisor hypomineralization and dental caries. Int J Paediatr Dent 27(1):11-21. https://doi.org/10.1111/ipd.12233

Andrade VM, Fontenele RC, de Souza AC, Almeida CA, Vieira AC, Groppo FC, Freitas DQ, Junior ED (2019) Age and sex estimation based on pulp cavity volume using cone beam computed tomography: development and validation of formulas in a Brazilian sample. Dentomaxillofac Radiol 48(7): 20190053. https://doi.org/10.1259/dmfr.20190053

Arora J, Talwar I, Sahni D, Rattan VJEJFS (2016) Secondary dentine as a sole parameter for age estimation: comparison and reliability of qualitative and quantitative methods among North Western adult Indians. Egypt J Forensic Sci 6(2):170-178

Asif MK, Nambiar P, Mani SA, Ibrahim NB, Khan IM, Lokman NB (2019) Dental age estimation in Malaysian adults based on volumetric analysis of pulp/tooth ratio using CBCT data. Leg Med (Tokyo) 36:50-58. https://doi.org/10.1016/j. legalmed.2018.10.005

Asif MK, Nambiar P, Mani SA, Ibrahim NB, Khan IM, Sukumaran P (2018) Dental age estimation employing $C B C T$ scans enhanced with mimics software: comparison of two different approaches using pulp/tooth volumetric analysis. J Forensic Leg Med 54:53-61. https://doi.org/10.1016/j.jflm.2017.12. 010

Bajpai M, Rahman F, Rani VJIJMD (2013) Estimation of age by attrition as a sole indicator. Indian J Multidisciplinary Dentistry 3(2):664-667

Cameriere R, Cunha E, Sassaroli E, Nuzzolese E, Ferrante L (2009) Age estimation by pulp/tooth area ratio in canines: study of a Portuguese sample to test Cameriere's method. Forensic Sci Int 193(1-3):128.e121-128.e1286. https://doi. org/10.1016/j.forsciint.2009.09.011

Cameriere R, De Luca S, Alemán I, Ferrante L, Cingolani MJF (2012) Age estimation by pulp/tooth ratio in lower premolars by orthopantomography. Forensic Sci Int 214(1-3):105-112

Carew RM, Errickson D (2019) Imaging in forensic science: five years on. J Forensic Radiol Imaging 16:24-33

Carvalho TS, Lussi A (2017) Age-related morphological, histological and functional changes in teeth. J Oral Rehabil 44(4):291-298. https://doi.org/10. 1111/joor.12474

De Angelis D, Gaudio D, Guercini N, Cipriani F, Gibelli D, Caputi S, Cattaneo CJ (2015) Age estimation from canine volumes. Radiol Med 120(8):731-736

Ekizoglu O, Inci E, Ors S, Kacmaz IE, Basa CD, Can IO, Kranioti EF (2019) Applicability of T1-weighted MRI in the assessment of forensic age based on 
the epiphyseal closure of the humeral head. Int J Leg Med 133(1):241-248. https://doi.org/10.1007/s00414-018-1868-7

Elmoazen R, Eldin MSS, Abd Alkhalek W (2017) Age estimation in an Egyptian population using pulp/tooth volume ratio obtained from cone beam computed tomography. Egypt Dent J 63:635-643

El-Sarnagawy G, Yasser S (2020) Effect of exposure to variable degrees and durations of heat on dental Barr body identification in females: an invitro cross-sectional study. J Int Oral Health 12(2):145-152. https://doi.org/10.4103/ jioh.jioh_239_19

Farhadian M, Salemi F, Saati S, Nafisi N (2019) Dental age estimation using the pulp-to-tooth ratio in canines by neural networks. Imag Sci Dentistry 49(1): 19-26. https://doi.org/10.5624/isd.2019.49.1.19

Gulsahi A, Kulah CK, Bakirarar B, Gulen O, Kamburoglu K (2018) Age estimation based on pulp/tooth volume ratio measured on cone-beam CT images. Dentomaxillofac Radiol 47(1):20170239-20170239. https://doi.org/10.1259/ dmfr.20170239

Hidayat S, Oscandar F, Malinda Y, Sasmita I, Dardjan M, Murniati N, Lita Y (2018) Human age estimation based on pulp volume of canines for chronological age estimation: preliminary research. Padjadjaran J Dentistry 30. https://doi. org/10.24198/pjd.vol30no3.19302

Jagannathan N, Neelakantan P, Thiruvengadam C, Ramani P, Premkumar P, Natesan A, Herald JS, Luder HU (2011) Age estimation in an Indian population using pulp/tooth volume ratio of mandibular canines obtained from cone beam computed tomography. J Forensic Odontostomatol 29(1):1-6

Juneja M, Devi YBK, Rakesh N, Juneja S (2014) Age estimation using pulp/tooth area ratio in maxillary canines-a digital image analysis. J Forensic Dent Sci 6(3):160-165. https://doi.org/10.4103/0975-1475.137047

Kavas AA, Tümen ECJIDR (2019) Volumetric pulp chambers measurements in mandibular and maxillary permanent first molar using cone-beam computed tomography by age and gender. Int Dent Res 9(1):30-40

Kazmi S, Mânica S, Revie G, Shepherd S, Hector M (2019) Age estimation using canine pulp volumes in adults: a CBCT image analysis. Int J Leg Med 133(6): 1967-1976. https://doi.org/10.1007/s00414-019-02147-5

Krasner P, Rankow H (2004) Anatomy of the pulp-chamber floor. J Endod 30 (1):5-16

Li G (2013) Patient radiation dose and protection from cone-beam computed tomography. Imag Sci Dentistry 43(2):63-69. https://doi.org/10.5624/isd.2013.43.2.63

Limdiwala PG, Shah JS (2013) Age estimation by using dental radiographs. J Forensic Dent Sci 5(2):118-122. https://doi.org/10.4103/0975-1475.119778

Marroquin TY, Karkhanis S, Kvaal SI, Vasudavan S, Kruger E, Tennant M (2017) Age estimation in adults by dental imaging assessment systematic review. Forensic Sci Int 275:203-211. https://doi.org/10.1016/j.forsciint.2017.03.007

Mathew DG, Rajesh S, Koshi E, Priya LE, Nair AS, Mohan A (2013) Adult forensic age estimation using mandibular first molar radiographs: a novel technique. J Forensic Dent Sci 5(1):56-59. https://doi.org/10.4103/0975-1475.114552

Melo M, Ata-Ali J (2017) Accuracy of the estimation of dental age in comparison with chronological age in a Spanish sample of 2641 living subjects using the Demirjian and Nolla methods. Forensic Sci Int 270:276.e271-276.e277. https://doi.org/10.1016/j.forsciint.2016.10.001

Muñoz A, Maestro N, Benito M, Sánchez JA, Márquez-Grant N, Trejo D, Ríos L (2018) Sex and age at death estimation from the sternal end of the fourth rib. Does Işcan's method really work? Leg Med (Tokyo) 31:24-29. https://doi. org/10.1016/j.legalmed.2017.12.002

Nemsi H, Haj Salem N, Bouanene I, Ben Jomaa S, Belhadj M, Mosrati MA, Aissaoui A, Ben Amor F, Chadly A (2017) Age assessment in canine and premolar by cervical axial sections of cone-beam computed tomography. Leg Med (Tokyo) 28:31-36. https://doi.org/10.1016/j.legalmed.2017.07.004

Salemi F, Farhadian M, Sabzkouhi BA, Saati S, Nafisi NJEJFS (2020) Age estimation by pulp to tooth area ratio in canine teeth using cone-beam computed tomography. Egypt J Forensic Sci 10(1):2

Saxena S (2011) Age estimation of indian adults from orthopantomographs. Braz Oral Res 25(3):225-229. https://doi.org/10.1590/s1806-83242011005000009

Scarfe WC, Farman AG (2008) What is cone-beam CT and how does it work? Dent Clin N Am 52(4):707-70v. https://doi.org/10.1016/j.cden.2008.05.005

Schmeling A, Dettmeyer R, Rudolf E, Vieth V, Geserick G (2016) Forensic age estimation. Deutsches Arzteblatt Int 113(4):44-50. https://doi.org/10.3238/ arztebl.2016.0044

Singal K, Sharma N, Kumar V, Singh P (2019) Coronal pulp cavity index as noble modality for age estimation: a digital image analysis. Egypt J Forensic Sci 9(1):42. https://doi.org/10.1186/s41935-019-0150-6

Tardivo D, Sastre J, Catherine JH, Leonetti G, Adalian P. Foti B (2014) Age determination of adult individuals by three-dimensional modelling of canines. Int J Leg Med 128(1):161-169. https://doi.org/10.1007/s00414-0130863-2

Tardivo D, Sastre J, Ruquet M, Thollon L, Adalian P, Leonetti G, Foti B (2011) Three-dimensional modeling of the various volumes of canines to determine age and sex: a preliminary study. J Forensic Sci 56(3):766-770. https://doi.org/ 10.1111/j.1556-4029.2011.01720.x

Tjäderhane L, Paju S (2019) Dentin-pulp and periodontal anatomy and physiology, pp 11-58

Uğur Aydın Z, Bayrak S (2019) Relationship between pulp tooth area ratio and chronological age using cone-beam computed tomography images. J Forensic Sci 64(4):1096-1099. https://doi.org/10.1111/1556-4029.13986

Vandana KL, Haneet RK (2014) Cementoenamel junction: an insight. J Indian Soc Periodontol 18(5):549-554. https://doi.org/10.4103/0972-124X.142437

Venkatesh S, Ajmera S, Ganeshkar SV (2014) Volumetric pulp changes after orthodontic treatment determined by cone-beam computed tomography. J Endod 40(11):1758-1763. https://doi.org/10.1016/j.joen.2014.07.029

Yilmaz F, Sonmez G, Kamburoglu K, Koc C, Ocak M, Celik HH (2019) Accuracy of $\mathrm{CBCT}$ images in the volumetric assessment of residual root canal filling material: effect of voxel size. Niger J Clin Pract 22(8):1091-1098. https://doi. org/10.4103/njcp.njcp_678_18

Zaher JF, Fawzy IA, Habib SR, Ali MM (2011) Age estimation from pulp/tooth area ratio in maxillary incisors among Egyptians using dental radiographic images. J Forensic Leg Med 18(2):62-65. https://doi.org/10.1016/j.jflm.2010.12.004

\section{Publisher's Note}

Springer Nature remains neutral with regard to jurisdictional claims in published maps and institutional affiliations.

\section{Submit your manuscript to a SpringerOpen ${ }^{\circ}$ journal and benefit from:}

- Convenient online submission

- Rigorous peer review

- Open access: articles freely available online

- High visibility within the field

- Retaining the copyright to your article

Submit your next manuscript at $\boldsymbol{\nabla}$ springeropen.com 